\title{
INITIATING FACTORS OF COMPLICATIONS DEVELOPMENT DURING PROSTHETICS OF TEETH WITH FIXED PROSTHESES
}

DOI: 10.36740/WLek202105122

\author{
Volodymyr B. Radchuk, Nataliia V. Hasiuk, Stepan S. Bozhyk, Tetiana I. Dzetsiukh, Iryna V. Antonyshyn \\ I. HORBACHEVSKY TERNOPIL NATIONAL MEDICAL UNIVERSITY, TERNOPIL, UKRAINE
}

\begin{abstract}
The aim: Determination of the factors complications occurrence in prosthetics with metal-ceramic prostheses.

Materials and methods: Clinical, cytological, cytochemical methods and methods of statistical processing of the received data are applied.

Results: A number of factors with different degrees of significance have been identified, which in the dynamics of clinical observations of the percentage of absorbed dispersion are decisive in the development of changes in the gums. At the stage of odontopreparation - the $1 \mathrm{factor}$, with the percentage of absorbed dispersion (12,3\%) - preparation. The 2 factor - (11,9\%) - traumatic. The 3 factor, periodontal, was slightly less significant $(9,8 \%)$. In the dynamics of clinical observations for 45 days in the first place was the dissecting factor - (14\%). The second most important factor was the vitality of the teeth - (11,5\%). The 3 factor remained relatively stable - periodontal (8,5\%). In the dynamics of clinical observations after 1 year, a redistribution of significance was noted. The largest percentage of absorbed dispersion covered periodontal factor - (15\%). Vitality factor - (11\%). Slightly lower, but clinically significant, of (8\%) absorbed dispersion, was the preparation factor.

Conclusions: Statistical analysis of the studied parameters made it possible to determine the key factors for predicting their development and diagnostics, it is important for organizing an increase in the effectiveness of orthopedic prophylactic therapeutic measures at the stages of restoration of dental hard tissues.
\end{abstract}

KEY WORDS: metal-ceramic dentures, gingivitis, localized periodontitis, odontopreparation

Wiad Lek. 2021;74(5):1164-1168

\section{INTRODUCTION}

One of the main tasks of orthopedic dentistry is the adequate restoration of defects in hard tissues of teeth and dentition, taking into account the individualized dental status of each patient [1]. The issues of reactive changes in the gums depending on the type of odontopreparation in the context of predicting long-term results of prosthetics taking into account an individualized approach are insufficiently studied. The issue of rehabilitation of dental patients with partial defects of the dentition and hard tissues of the teeth, based on the provisions of the use of various types of odontopreparation, taking into account the fact of the vitality of the pulp and compensatory-adaptive changes in the gums in the dynamics of orthopedic treatment [2].

\section{THE AIM}

Determination of risk factors for complications after prosthetics with metal-ceramic prostheses, based on the results of clinical, paraclinical studies and statistical analysis. To achieve this aim, it is necessary to determine and statistically substantiate the factors that initiate changes in the gums that arise as a result of various types of odontopreparation for metal-ceramic crowns, in the dynamics of clinical observations.

\section{MATERIALS AND METHODS}

To solve the aim and problem, clinical, cytological, cytochemical methods and methods of statistical processing of the data obtained were used. Formed 2 main groups of young male patients (25-44 years in accordance with the WHO age classification) in a total of 40 people, depending on the type of odontopreparation used, the state of the dental pulp and the complex of planned studies in the dynamics of clinical observations after prosthetics with metal-ceramic prostheses (Table I).

Patients of the I group underwent odontopreparation under with a beveled rounded shoulder in the area of the tooth neck, and patients of the II group - with maximum preservation of hard tissues - the formation of a shoulder symbol. The studies were carried out on the teeth of the chewing group of both jaws, based on the data of morphological studies of H. Shillingburg, C. Grace (1973), J. Woelfel (1991-1993), A. Vorobets (2017) [3].

Statistical processing of the obtained data was carried out using the «Statistica» licensed program of the Stat Soft Company. The obtained indicators were processed by methods of mathematical statistics with the calculation of the average sample values $(\mathrm{M})$ and errors of the average values $(\mathrm{m})$. Parametric methods stalled for indicators, the distribution of which corresponded to the normal distribution law. Compliance was checked by the Shapiro- 
Table I. Distribution of the examined persons by observation groups

\begin{tabular}{ccccc}
\hline $\begin{array}{c}\text { Group of clinical } \\
\text { observation objects }\end{array}$ & Type of odontopreparation & $\begin{array}{c}\text { Number of clinical } \\
\text { observations objects }\end{array}$ & \multicolumn{2}{c}{ Depending on the condition of the pulp } \\
\cline { 3 - 5 } & with shoulder & 21 & 11 & vital \\
\hline II & with the symbol of the shoulder & 19 & 10 & 9 \\
\hline
\end{tabular}

Wilk test and Student's t-test. Differences were considered significant with an error $p<0,05[4,5]$. In cases where the distribution law was statistically significantly different from the normal one, the nonparametric Mann-Whitney test (U) was calculated as a nonparametric analogue of the Student's t-test for independent samples. The method of factor analysis was used to quantitatively measure the influence of factor signs, to determine the likelihood and intensity of the impact and its confidence limits in causal models. To analyze the relationship of quantitative parameters that were studied, the Spearman correlation coefficient (r) was determined. The correlation coefficient was considered statistically significant at $\mathrm{p}<0,05$.

The Bioethics Commission of the I. Horbachevsky Ternopil National Medical University of the Ministry of Health of Ukraine, at its meeting (except from the protocol No. 62 dated 11.01.2021) reviewed the research materials and determined that when working with patients, the general ethical Rules of humane treatment of patients were observed in accordance with the requirements of the Tokyo Declaration of the World Medical Association, the International Recommendations of the Helsinki Declaration of Human Rights, the Council of Europe Convention on Human Rights and Biomedicine [6].

\section{RESULTS}

In the dynamics of clinical observations on the 45th day, the presence of an inflammatory process in the gums in patients of both groups was recorded, with a high intensity of inflammation of the gums in the patients of the I group with trauma to the gingival margin at the time of odontopreparation, which correlates with the deterioration of the hygiene index according to Green-Vermillion $(2,17 \pm 0,01)$, increased PMA $(25,25 \pm 0,32)$ and papillary bleeding index (PBI) according to Muhlemann and Saxer $(4,24 \pm 0,03)$ and PI according to Russel $(0,78 \pm 0,01)$. After 1 year, the progression of the inflammatory process was observed in all observation groups, however, the process acquired the maximum expression in patients of the II group when preparing vital teeth, directly correlates with the indicators of the Green-Vermillion hygiene index $(2,65 \pm 0,08)$, an increase in the PMA indicator $(35,40 \pm 1,21)$, papillary bleeding index (PBI) according to Muhlemann and Saxer $(6,71 \pm 0,25)$ and PI index according to Russel $(1,55 \pm 0,05)$, which is interpreted as periodontitis of the initial stage.

The cellular composition of the gums of patients of both groups in the dynamics of clinical observations was characterized by an intensive restructuring of the epithelial and connective tissue components, reflecting changes in the type of keratinization and desquamation of the epithelium due to a violation of the differentiation of various forms of epithelial cells due to the infiltration of the lamina propria cells of the inflammatory reaction, provided the maximum expression of alternative processes on the 45th day in of persons of the I group, when the gingival margin is injured, correlates with the index scores. A year later, there was an increase in the number of glycogen epithelial cells, which was due to the activation of glycolytic processes as a result of the redistribution of glycogen in the cells of the intermediate layer, which is characteristic of the inflammatory process. Qualitative changes in epithelial cells were manifested by the appearance of cells with signs of dystrophic changes and cytopathology, with the maximum expression in patients of the II group during the preparation of vital teeth.

Objectification of the dynamics of the studied indicators of the dental status, the type of odontopreparation, the fact of trauma to the gingival margin, the vitality of the teeth to be prepared, made it possible to determine the presence of reliable changes in a number of parameters. It is advisable to note that, according to the 12 parameters taken before the calculation, significant changes at different periods of observation were recorded for 4 parameters with the eigenvalues of the components greater than 1,0 , which together absorbed more than $83 \%$ of the total variance, and the first 3 main components (factors) accounted for $34 \%$ of the total variance. The results of the applied factor analysis made it possible to obtain and highlight the key factors that, at different times, observations are leading in the development of inflammatory processes in the gums, and to trace the dynamics of their change in different periods of using orthopedic structures. The first factor, which has a high percentage of absorbed dispersion $(12,3 \%)$, covers the fact of the vitality of the prepared tooth in relation to the type of odontopreparation, we named the preparation. The second factor is equal in dispersion of absorption of signs (11,9\%), including indicators of the type of odontopreparation and the factor of injury to the gingival margin - traumatic. The third factor turned out to be somewhat less significant in this term $(9,8 \%$ of the variance), which included indicators of the type of odontopreparation in conjunction with indicators of hygiene - periodontal.

In the dynamics of clinical observations on the 45th day, there was a redistribution of the significance of factors. In the first place in terms of importance was the preparation factor ( $15 \%$ of the absorbed dispersion), which was formed as a result of the strengthening of the relationship between 


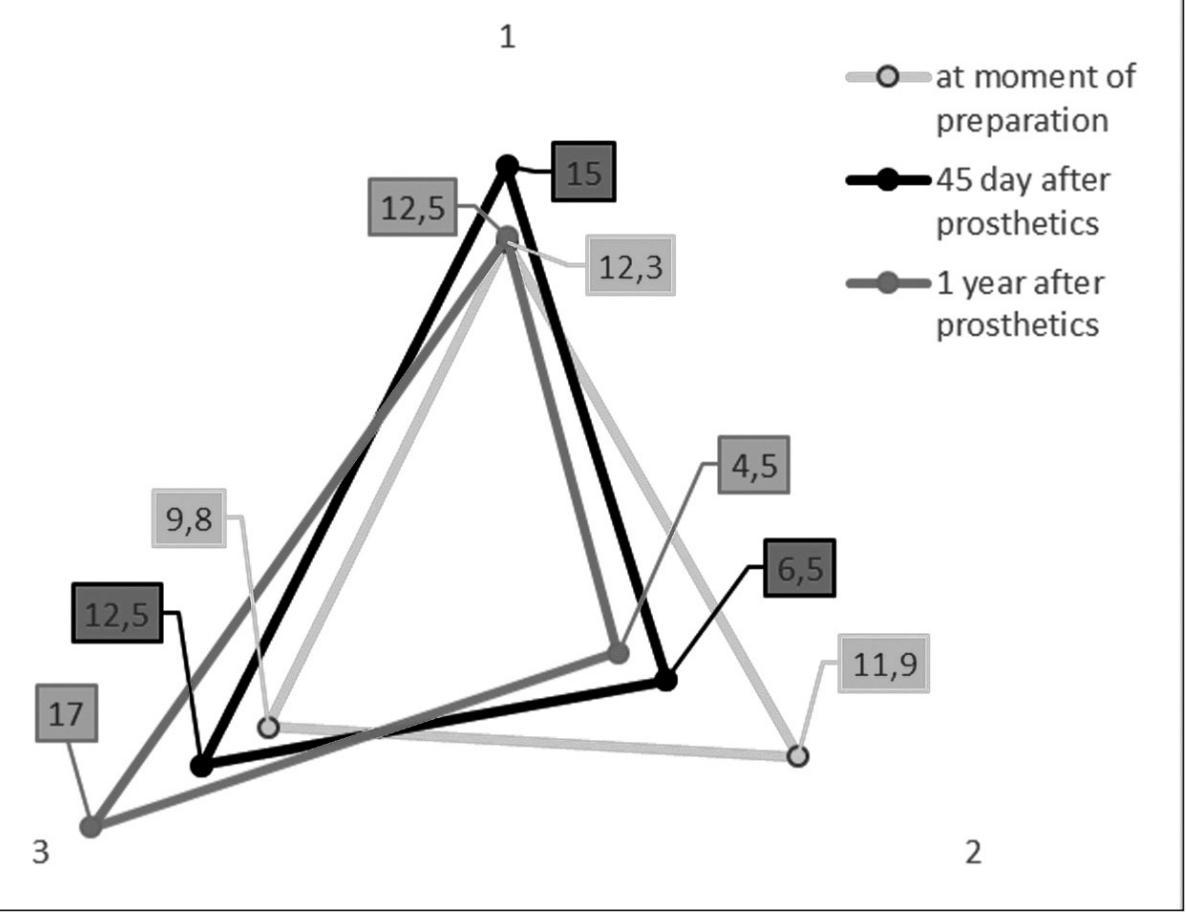

Fig. 1. Distribution of the significance of risk factors for complications during prosthetics with metal-ceramic prostheses in the dynamics of clinical observations.

1 - preparation factor;

2 - traumatic factor;

3 - periodontal factor. the odontopreparation factor and the tooth vitality factor. The results obtained indicate local circulatory disorders, which subsequently initiate degenerative changes in the bodies and processes of odontoblasts, which, in turn, affects the trophism of dentin and enamel from hard tissues and disrupts trophism in the gingival epithelium due to the vessels of the basement membrane and lamina propria. The redistribution of significance took place between the second and third factors. In second place in terms of the percentage of dispersion of absorption of signs, the periodontal factor was recorded, including indicators of the index assessment of the state of periodontal tissues and the type of odontopreparation was applied. This factor accounts for 12,5\% of the absorbed variance. With a significantly lower percentage of absorbed dispersion $(6,5 \%)$, the third factor appeared in this observation term, which includes indicators of the type of odontopreparation and the fact of trauma to the gingival margin - traumatic. A decrease in the percentage of absorbed dispersion is due to the timing of gum epithelialization.

In the dynamics of clinical observations after 1 year, a redistribution of the significance of factors was revealed. The first place was taken by the factor ( $17 \%$ of the absorbed dispersion), which was formed due to the strengthening of the relationship between the parameters of the index assessment of the state of periodontal tissues and the type of odontopreparation - the so-called periodontal. The factor formed by the degree of vitality of the tooth and the type of odontopreparation is quite high, which is $12,5 \%$ of the dispersion - preparative. A significantly lower percentage, but clinically significant with $4,5 \%$ of absorbed dispersion, is the traumatic factor formed between the indicators of the type of odontopreparation and the fact of trauma to the gingival margin. The fact of trauma to the gingival margin during the observation period of 1 year has no significant effect. This gives grounds to assert that the type of odontopreparation is decisive in the formation of this factor (Figure 1).

The use of the method of the main components made it possible to identify a number of factors that are fundamentally significant for the development of the inflammatory process in the periodontal tissues at different periods of clinical observations - these are dissection, traumatic and periodontal. Their significance and qualitative characteristics change at different periods of clinical observations and have their own characteristics that should be paid attention to. Of particular relevance on the 45th day is the dissection factor, which is the initiator in the development of inflammatory changes in the gums, which quite logically explains the redistribution of factors during the annual period of clinical observations, in which the periodontal factor acquires the greatest significance. The latter, according to the degree of absorbed dispersion, is an objective need for the treatment of periodontal tissues in individuals of both groups, it is fundamentally significant for organizing an increase in the effectiveness of orthopedic interventions and preventive medical measures.

The results of the analysis with the subsequent determination of factors that, at different periods of clinical observations, depending on the degree of absorbed dispersion, affect the results of orthopedic treatment, made it possible to identify chains of interconnection between the type of odontopreparation and risk factors for changes in the gums [7].

\section{DISCUSSION}

The results of studying the state of a number of parameters in patients of both groups in the dynamics of clinical observations and elucidating the analysis of their 
interrelationships to determine the main factors of the onset and development of changes in the gums based on factor analysis allow us to draw the following conclusions.

The cellular composition of the gums of patients of both groups in the dynamics of clinical observations was characterized by an intensive restructuring of the epithelial and connective tissue components, reflecting changes in the type of keratinization and desquamation of the epithelium due to a violation of the differentiation of various forms of epithelial cells due to the infiltration of the lamina propria cells of the inflammatory reaction, provided the maximum expression of alternative processes on the 45th day in persons of the I group, with trauma to the gingival margin, correlates with the indexes. A year later, there was an increase in the number of glycogen epithelial cells, which was due to the activation of glycolytic processes as a result of the redistribution of glycogen in the cells of the intermediate layer, which is characteristic of the inflammatory process. Qualitative changes in epithelial cells were manifested by the appearance of cells with signs of dystrophic changes and cytopathology, with the maximum expression in patients of the II group during the preparation of vital teeth.

The results of studying the cellular composition of the gums of the patients of both observation groups after the odontopreparation differed in quality characteristics, since the fact of trauma to the gingival margin during manipulation was taken into account to predict the effect of various types of odontoreparation on the gum condition. The frequency of gingival margin injuries during the preparation of devital teeth for metal-ceramic constructions is $42 \%$, regardless of its type and is consistent with the results of A.N. Doroshenko and M.V. Doroshenko that $37 \%$ of patients develop clinically pronounced inflammatory changes in the marginal periodontium. Injury to the gingival margin during preparation is more often observed when processing vital teeth, and, according to our data, is $76,5 \%$ [8].

The obtained results of clinical observations are consistent with the works of I.I. Palivoda regarding the effect of artificial crowns on the state of the marginal periodontium of abutment teeth, which is manifested by inflammatory changes in the marginal edge of the gum with subsequent recession of the gingival margin of the abutment teeth, actualizes the issue of the mandatory expediency of preparation with the creation of a classic ledge at the level of the gingival margin. Comparison of the obtained research results with the developments of I.I. Palivoda explains the varied dynamics of the inflammation indices on the 45th day and 1 year and explains the different activity of the inflammatory process in the gums at different periods of observation [9].

The cellular composition of the gums underwent changes in the epithelial and connective tissue components, and was characterized by the appearance of single basal epithelial cells and a significant number of inflammatory cells, reflecting increased phagocytosis. The given cellular composition corresponds to the clinical picture of exacerbation of localized periodontitis in the area of orthopedic structures in patients of the I group, who underwent preparation of vital teeth for metal-ceramic structures $[10,11]$.

\section{CONCLUSIONS}

To achieve this goal and solve problems in the course of the study, an integrated approach was developed and applied using clinical, cytological, cytochemical, statistical studies. The adequacy of their selection in the process of statistical processing provides reliability and comprehensively substantiates the data obtained with minimization of technological and systematic errors. The conducted factor analysis of the studied parameters made it possible to identify the main directions of changes initiated by orthopedic interventions and made it possible to determine the key parameters for predicting their development and diagnosis, it is fundamentally important for organizing an increase in the effectiveness of orthopedic interventions and preventive therapeutic measures at the stages of restoration of hard tissues of teeth and dentition.

\section{REFERENCES}

1. Nam S.J., Yoon M.J., Kim W.H. et al. Marginal and internal fit of conventional metal-ceramic and lithium disilicate CAD/CAM crowns. Int J Prosthodont. 2015;28(5):519-21.

2. Carvalho T.S., Lussi A. Age-related morphological, histological and functional changes in teeth. J Oral Rehabil. 2017;44(4):291-8.

3. Hasiuk P., Vorobets A., Hasiuk N. et al. Sex differences of odontometrical indexes crowns of molars. Interventional Medicine \& Applied Science. 2017;9(3):160-3.

4. Narayanan R., Nugent R., Nugent K. An investigation of the variety and complexity of statistical methods used in current internal medicine literature. South Med J. 2015;108(10):629-34.

5. Habibzadeh F. Statistical data editing in scientific articles.J Jorean Med Sci. 2017;32(7):1072-6.

6. Shrestha B., Dunn L. The Declaration of Helsinki on Medical Research involving Human Subjects: A Review of Seventh Revision. J Nepal Health Res Counc. 2020;17(4):548-52.

7. Pjetursson B.E., Valente N.A., Strasding M. et al. A systematic review of the survival and complication rates of zirconia-ceramic and metalceramic single crowns. Clin Oral Implants Res. 2018;29(16):199-214.

8. Doroshenko 0.M., Doroshenko M.V. Otsinka stanu marhinal'noho parodontu v zalezhnosti vid metodyky preparuvannya opornykh zubiv pid chas vyhotovlennya neznimnykh konstruktsiy zubnykh proteziv. [Assessment of the condition of the marginal periodontium depending on the method of preparation of abutment teeth during the manufacture of fixed structures of dentures]. Collection of scientific works of PL Shupyk NMAPE staff. 2013;22(3):42-8. (in Ukrainian).

9. Palyvoda I.I. Vplyv shtuchnykh koronok na stan marhinal'noho parodonta opornykh zubiv. [Influence of artificial crowns on the condition of the marginal periodontium of abutment teeth]. Ukrainian Dental Almanac. 2011;3:49-51. (in Ukrainian).

10. Hasiuk N.V. Patohenetychni mekhanizmy tsytolohichnoyi perebudovy slyzovoyi obolonky porozhnyny rota u khvorykh na heneralizovanyy parodontyt. [Pathogenetic mechanisms of cytological rearrangement of the oral mucosa in patients with generalized periodontitis]. Bulletin of scientific research. 2015;1:63- 6. (in Ukrainian). 
11. Radchuk V.B., Hasiuk N.V., Hasiuk P.A. et al. Characteristics of changes in the cellular composition of gums in the dynamics of clinical observations, depending on the type of odontopreparation for cermet structures. Journal of Clinical and Experimental Medical Researches. 2018:4(6):389-95.

The work was performed as part of research work of the Department of Therapeutic Dentistry "Increasing the effectiveness of dental care patients with primary and secondary lesions of the tissues of the oral cavity based on the study of the patterns of the clinical course and chains of pathogenesis» (state registration number 0120U104151).

\section{ORCID and contributionship:}

Volodymyr B. Radchuk: 0000-0001-9019-6008 B, C, D

Nataliia V. Hasiuk: 0000-0002-6798-9090 A, E, F

Stepan S. Bozhyk: 0000-0002-2748-2308 B,D

Tetiana I. Dzetsiukh: 0000-0001-7163-1844 ${ }^{D, E}$

Iryna V. Antonyshyn: 0000-0002-1252-9177 C, F

\section{Conflict of interest:}

The Authors declare no conflict of interest.

\section{CORRESPONDING AUTHOR} Volodymyr B. Radchuk

I.Horbachevsky Ternopil National Medical University, 1 Maidan Voli st., 46001 Ternopil, Ukraine tel: +380977517274

e-mail: radchuk@tdmu.edu.ua

Received: 09.12.2020

Accepted: 29.03.2021

A - Work concept and design, B - Data collection and analysis, C - Responsibility for statistical analysis, D-Writing the article, $\mathbf{E}$-Critical review, $\mathbf{F}$ - Final approval of the article 